\title{
Non-inflammatory cerebrospinal fluid delays the diagnosis and start of immunotherapy in anti-NMDAR encephalitis
}

\author{
La ausencia de hallazgos de inflamación en líquido cefalorraquídeo retrasa el inicio de \\ inmunoterapia en la encefalitis anti-NMDAR
}

Mariana Espinola-Nadurille ${ }^{1,2}$, Paola Bautista-Gomez', Jose Flores ${ }^{3}$, Veronica Rivas-Alonso33, Rodrigo Perez-Esparza ${ }^{4}$,Rodolfo Solís-Vivanco ${ }^{5,6}$, Steven Vargas-Cañas ${ }^{3}$

\begin{abstract}
Anti-N-methyl-D-aspartate receptor (anti-NMDAR) encephalitis is a form of autoimmune encephalopathy that presents with a wide variety of symptoms, including neuropsychiatric manifestations. The authors' aim for this study was to analyze the results of paraclinical studies of patients with a diagnosis of anti-NMDAR encephalitis and the association between symptom onset and diagnosis, and start of immunotherapy. Retrospective data of 29 patients with anti-NMDAR encephalitis were gathered and analyzed. Abnormal EEG was found in 27 patients (93.1\%), whereas MRI was abnormal in 19 patients (65.5\%). In contrast, an inflammatory pattern on CSF analysis was found in only 13 patients (44.8\%). The absence of pleocytosis or increased proteins in the CSF was associated with a longer time from symptom onset to diagnosis and treatment $(p=0.003)$. The authors conclude that noninflammatory CSF may delay the correct diagnosis and start of immunotherapy in anti-NMDAR encephalitis. In the presence of suggestive clinical features, extensive studies including EEG are recommended.
\end{abstract}

Keywords: anti-n-methyl-d-aspartate receptor encephalitis; cerebrospinal fluid; diagnosis.

\section{RESUMEN}

La encefalitis por receptor anti-N-metil-D-aspartato (anti-NMDAR) es una encefalopatía autoinmune con una amplia variedad de síntomas, incluyendo manifestaciones neuropsiquiátricas. Nuestro objetivo en este estudio fue analizar los resultados paraclínicos de pacientes diagnosticados con encefalitis anti-NMDAR y la asociación entre inicio de sintomatología, el diagnóstico y el inicio de inmunoterapia. Encontramos un EEG anormal en 27 pacientes (93.1\%), asi como IRM anormal en 19 de ellos (65.5\%). En contraste, el análisis de LCR mostró un patrón inflamatorio en tan solo 13 pacientes (44.8\%). La ausencia de pleocitosis o proteínas incrementadas en el LCR se asoció con un mayor tiempo desde el inicio de la sintomatología hasta el inicio del tratamiento $(p=0.003)$. Concluimos que el LCR no inflamatorio puede retrasar el diagnóstico correcto y el inicio de tratamiento en encefalitis anti-NMDAR, por lo que se recomienda la realización de estudios exhaustivos, incluyendo EEG, ante la presencia de indicadores clínicos sugerentes del padecimiento.

Palabras clave: encefalitis antirreceptor n-metil-d-aspartato; líquido cefalorraquídeo; diagnóstico.

Encephalitis is an inflammation of brain parenchyma associated with neurologic dysfunction that causes substantial morbidity and mortality worldwide. Specific etiologies are identified in less than $50 \%$ of cases $^{1}$. In 2013, in an attempt to better define cases, the International Encephalitis Consortium proposed the Diagnostic Criteria for Encephalitis and Encephalopathy of Presumed Infectious or Autoimmune Etiology. The major criterion is altered mental status (defined as decreased or altered level of consciousness, lethargy, or personality change) for 24 hours or more, with no alternative cause identified. Minor criteria (two for possible encephalitis; three or more for probable encephalitis) are clinical features

\footnotetext{
${ }^{1}$ Instituto Nacional de Neurología y Neurocirugía, Unidad de Neuropsiquiatría, Ciudad de México, México

2Universidad Nacional Autónoma de México, Facultad de Medicina, División de Posgrado, Ciudad de México, México

${ }^{3}$ Instituto Nacional de Neurología y Neurocirugía, Subdirección de Neurología, Ciudad de México, México

4 Instituto Nacional de Neurología y Neuricrugía, Laboratorio de Investigación en Adicciones, Ciudad de México, México

${ }^{5}$ Instituto Nacional de Neurología y Neurocirugía, Departamento de Neuropsicología, Ciudad de México, México

6Universidad Nacional Autónoma de México, Facultad de Psicología, Ciudad de México, México.
}

Correspondence: Steven Vargas-Cañas; Subdirección de Neurología. Instituto Nacional de Neurología y Neurocirugía. Insurgentes Sur 3877. Tlalpan. ZC 14269 Mexico City; E-mail: stevenvc@hotmail.com

Conflict of interest: There is no conflict of interest to declare.

Received 03 August 2017; Received in final form 26 September 2017; Accepted 29 September 2017. 
of documented fever $\geq 38^{\circ} \mathrm{C}\left(100.4^{\circ} \mathrm{F}\right)$, generalized or partial seizures, or new onset of focal neurologic findings; and paraclinical features of cerebrospinal fluid (CSF) white blood cell count $\geq 5 / \mathrm{mm}^{3}$, abnormality of brain parenchyma on neuroimaging, or electroencephalogram (EEG) abnormality ${ }^{1}$.

Anti-N-methyl-D-aspartate receptor encephalitis (antiNMDAR encephalitis) is an autoimmune encephalopathy characterized by the presence of serum and CSF IgG antibodies against the GluN1 subunit of NMDAR, a neuronal surface synaptic receptor, affecting children, adolescents and adults $^{2}$. In adults, it presents with psychiatric, behavioral, and cognitive symptoms at onset and, less frequently, seizures ${ }^{3,45}$. Over the first four weeks, most patients develop movement disorders, loss of consciousness, autonomic dysfunction, and central hypoventilation. Early diagnosis and immunotherapy have consistently been reported to improve the outcome ${ }^{4,6,7}$. Since antibody testing for a definite diagnosis of anti-NMDAR encephalitis is not readily accessible in many institutions, recent guidelines have recommended starting immunotherapy in the face of suggestive clinical symptoms, in addition to supportive findings in diagnostic tests such as CSF analysis, EEG and magnetic resonance imaging (MRI), and reasonable exclusion of other disorders ${ }^{8}$.

The National Institute of Neurology and Neurosurgery (NINN) of Mexico is a neurological referral center for adults that continuously receives patients with new onset psychiatric or behavioral symptoms at the emergency department, transferred from psychiatric and general hospitals in Mexico City and nearby provinces, in order to rule out neurological etiologies, particularly encephalitis. The general assessment includes a clinical history, vital signs, a neurological examination, and paraclinical investigations such as general laboratory studies, brain computed tomography scans, and cytochemical CSF analysis. Electroencephalography and MRI are not readily available for the assessment of all patients in the emergency department. In the absence of findings suggestive of neurological disease, patients are referred back to the hospitals of origin.

We describe the paraclinical results of patients with anti-NMDAR encephalitis diagnosed at the NINN, and their association with the time of onset of symptoms and preliminary diagnosis of anti-NMDAR, as well as the start of immunotherapy.

\section{METHODS}

From January 2014 to December 2016, 29 patients diagnosed with definite anti-NMDAR encephalitis according to previously-suggested criteria ${ }^{9}$ were included in this analysis. As part of their assessment, CSF cytochemical analysis, EEG and MRI were performed in all patients. The CSF was obtained upon patient arrival, but due to availability, the time to EEG and MRI depended on clinical and CSF findings.
Serum and CSF antibodies against the NR1 subunit of the NMDA glutamate receptor were processed for all patients at Labco Nous Diagnostics, Barcelona, Spain with rat brain immunohistochemistry and cell-based assays with NMDA expressing cells. Other findings such as the presence of systemic tumors and CSF oligoclonal bands were assessed. The study protocol was revised and approved by the Ethics Committee of the NINN, and it conforms to the provisions of the Declaration of Helsinki in 1995 (revised in Edinburgh, 2000). Statistical analysis included descriptive data (central tendency and dispersion measures, and frequencies as needed). Also, we compared the time from symptom onset to start of treatment between positive and negative paraclinical studies using nonparametric tests (Mann-Whitney U). Statistical significance was established in $p<0.05$. All statistical analyses were done using SPSS 20.0.

\section{RESULTS}

Our sample included 16 women (55.2\%). The mean age of all participants was $26.1 \pm 9$ years and mean education was $10.7 \pm 3$ years. Complete description of the clinical presentation of this sample will be part of a future report. Cytochemical CSF analysis acquired $12.6 \pm 8$ days from symptom onset, revealed an inflammatory pattern (with pleocytosis, and/or increased proteins) in only 13 (44.8\%) patients. The CSF oligoclonal band screens were performed in 19/29 patients and were found in 11 . The EEGs acquired $22.7 \pm 13$ days from symptom onset were abnormal (with focal or diffuse slow activity, epileptic activity, or extreme delta brush) in 27 (93.1\%) patients, and MRIs acquired $26.3 \pm 12$ days from symptom onset were abnormal (unilateral or bilateral medial temporal lobes, focal cortical and/or insulae hyperintensities on T2-FLAIR sequence) in 19 (65.5\%) patients. Table 1 shows the relationship of paraclinical results and days from onset of symptoms to preliminary diagnosis of anti-NMDAR encephalitis. Normal CSF results delayed not only the start of immunotherapy, but also, as expected, the MRI and EEG examinations (MRI with normal CSF $=33.9 \pm 10$ vs. MRI with abnormal CSF $=16.3 \pm 6, \mathrm{U}=14, \mathrm{p}<0.001$; EEG with normal $\mathrm{CSF}=33.1 \pm 7$ vs. EEG with abnormal CSF $=10.8 \pm 6, \mathrm{U}=2$, $\mathrm{p}<0.001)$. Serum and CSF samples for antibodies against the NR1 subunit of NMDA glutamate receptor were acquired $24.2 \pm 15$ days from symptom onset, but since antibodies against NMDAR are processed abroad, the results were received 6-12 weeks after the samples were taken. Serum anti-NMDAR antibodies were positive in $22(75.8 \%)$ patients, and CSF antibodies were positive in 29 (100\%). All patients were screened for systemic tumors and four female patients underwent resection of ovarian teratoma.

The two patients with normal EEG also showed noninflammatory CSF and a normal MRI. In one patient, an abnormal 18-fluorodeoxyglucose PET scan that exhibited severe 
hypometabolism more prominent in the hippocampi, amygdalae, cingulum and occipital lobes, along with frontal asymmetric hypermetabolism in the left dorsolateral and orbitofrontal cortex, prompted the decision to start treatment. In the other patient, specific treatment was initiated two months after symptom onset when antibody testing results were received.

\section{DISCUSSION}

Anti-NMDAR encephalitis is a neuroimmunological disorder that usually presents with psychiatric and/or behavioral symptoms. Since antibody testing takes several weeks to obtain at the NINN, immunotherapy is initiated with a preliminary diagnosis based on clinical symptoms and supportive findings in CSF, EEG and MRI as recommended ${ }^{9}$.

One of the first case series of anti-NMDAR encephalitis reported by Dalmau et al. ${ }^{9}$, stated that many patients with anti-NMDAR encephalitis were initially assessed by psychiatrists or admitted to psychiatric centers, but subsequently developed complex neurological symptoms requiring multidisciplinary care that later facilitated the correct diagnosis in conjunction with CSF pleocytosis. More recently, it has been recognized that autoimmune encephalitis can present with core symptoms resembling an infectious etiology, but typically does not present with fever or CSF pleocyto$\operatorname{sis}^{2,8}$. In other reported case series, as reviewed in Table 2, initial noninflammatory CSF varied widely, in $15-96 \%$ of the patients. In our case series, more than half the patients did not show inflammatory CSF at the first evaluation, which is a concern as they may have been misdiagnosed as having a primary psychiatric disorder. This is supported by the finding that in patients who presented with an initial noninflammatory CSF, it took twice as long to perform the EEG and MRI compared with the patients with abnormal CSF. Also, in the former cases, it also took twice as long to initiate immunotherapy (Table 1). Misdiagnosing anti-NMDAR as a primary psychiatric disorder can have deleterious consequences. For instance, Lejuste et al. ${ }^{3}$ reported that more than $40 \%$ of their patients were initially hospitalized in psychiatric departments with a primary psychiatric diagnosis, even though most had presented with a neurologic symptom at their first emergency department evaluation. Besides delaying the correct diagnosis and specific treatment, many

Table 1. Comparison of paraclinical results with days from onset of symptoms to preliminary diagnosis of anti-NMDAR encephalitis.

\begin{tabular}{|c|c|c|c|c|}
\hline Variable & $\mathrm{n}(\%)$ & $\begin{array}{c}\text { Mean days from onset to } \\
\text { diagnosis (SD) }\end{array}$ & Range $(95 \% \mathrm{Cl})$ & $p$ value* \\
\hline \multicolumn{5}{|l|}{ CSF cytochemical } \\
\hline Inflammatory & $13(44.8)$ & $22.9 \pm 13$ & $10-50$ & \\
\hline Noninflammatory & $16(55.2)$ & $40.2 \pm 15$ & $13-85$ & 0.003 \\
\hline \multicolumn{5}{|l|}{ EEG } \\
\hline Abnormal & $27(93.1)$ & $30.5 \pm 14$ & $10-59$ & \\
\hline Normal & $2(6.9)$ & $58.5 \pm 37$ & $32-85$ & 0.18 \\
\hline \multicolumn{5}{|l|}{ MRI } \\
\hline Abnormal & $19(65.5)$ & $30.1 \pm 13$ & $11-56$ & \\
\hline Normal & $10(34.5)$ & $36.9 \pm 22$ & $10-85$ & 0.60 \\
\hline
\end{tabular}

Table 2. Results of abnormal CSF, EEG and MRI findings in different case series.

\begin{tabular}{|c|c|c|c|c|}
\hline Study & $\mathrm{n}$ & Abnormal CSF n (\%) & Abnormal EEG n (\%) & Abnormal MRI n (\%) \\
\hline Dalmau et al. ${ }^{9}(2008)$ & 100 & $95(95 \%)$ & $92(92 \%)$ & $55(55 \%)$ \\
\hline Florance et al. ${ }^{10}(2009)$ & 32 & $31(96.9 \%)$ & $25(78.1 \%)$ & $10(31.2 \%)$ \\
\hline Irani et al.11 (2010) & 44 & $30(68.2 \%)$ & $35(79.5 \%)$ & $5(11.4 \%)$ \\
\hline Titulaer et al. ${ }^{4}$ (2013) & 557 & $418 / 532(78.6 \%)$ & $432 / 482(89.6 \%)$ & 180/540 (33.3\%) \\
\hline Viaccoz et al.12 (2014) & 71 & $56 / 62(90.3 \%)$ & 47/61 (77\%) & $25 / 69(36.2 \%)$ \\
\hline Zekeridou et al. ${ }^{13}$ (2015) & 36 & $32 / 35(91.4 \%)$ & $32 / 35(91.4 \%)$ & $11 / 35(31.4 \%)$ \\
\hline Sartori et al.? (2015) & 20 & $9 / 16(56.3 \%)$ & 19/19 (100\%) & $9(45 \%)$ \\
\hline Wang et al. ${ }^{5}$ (2016) & 51 & $32(62.7 \%)$ & $42 / 49(85.7 \%)$ & $20 / 50(40 \%)$ \\
\hline Wright et al.14 (2015) & 31 & $13 / 29(44.8 \%)$ & 28/30 (93.3\%) & $11(35.5 \%)$ \\
\hline Nagappa et al. ${ }^{15}$ (2016) & 13 & $2(15.4 \%)$ & $13(100 \%)$ & $2(15.4 \%)$ \\
\hline Zhang et al. ${ }^{16}$ (2017) & 432 & 186/320 (58.1\%) & $240 / 281(85.4 \%)$ & $137 / 342(40 \%)$ \\
\hline Our series & 30 & $13(43.3 \%)$ & $28(93.3 \%)$ & $19(63.3 \%)$ \\
\hline
\end{tabular}

CSF: Cerebrospinal fluid; EEG: Electroencephalogram; MRI: Magnetic resonance imaging. 
patients receive antipsychotic medications for the treatment of behavioral symptoms, which may lead to the development of neuroleptic malignant syndrome with complications reported in $47 \%^{3}$.

Thus, together with assessing for discreet neurological symptoms relevant to encephalitis, we recommend extending paraclinical investigations in patients with an acute episode of psychiatric symptomatology or behavioral changes if (a) the presentation is of less than 10 days in a previouslyhealthy individual, and/or (b) specific symptoms such as disorientation, attention disturbances, decreased awareness of the environment, catatonic symptoms, and history or signs of speech difficulties are present.

The EEG could be a diagnostic aid, given that in most case series, as in ours, it was abnormal in more than $90 \%$ of the cases (Table 2). However, a normal EEG does not necessarily exclude anti-NMDAR encephalitis, and neither does psychiatric, cognitive or behavioral symptomatology starting months or even years before assessment ${ }^{3}$.

In conclusion, we report the presence of noninflammatory CSF in almost $50 \%$ of patients with anti-NMDAR encephalitis. We propose cautious neurological decision making based on CSF results when excluding the presence of encephalitis, as the absence of CSF pleocytosis and/or increased proteins may delay not only diagnosis, but the ordering of complementary paraclinical investigations and the length of time to initiate immunotherapy in patients with delayed confirmation.

\section{ACKNOWLEDGEMENTS}

The authors thank Prof. Angela Vincent FRS F Med Sci Nuffield Department of Clinical Neurosciences, Oxford UK for her helpful suggestions to the manuscript.

\section{References}

1. Venkatesan A, Tunkel AR, Bloch KC, Lauring AS, Sejvar J, Bitnun A et al. Case definition, diagnosis algorithms, and priorities in encephalitis: consensus statement of the international encephalitis consortium. Clin Infect Dis. 2013;57(8):1114-28. https://doi.org/10.1093/cid/cit458

2. Leypoldt F, Armangue T, Dalmau J. Autoimmune encephalopathies. Ann NYAcad Sci. 2015;1338(1):94-114. https://doi.org/10.1111/nyas.12553

3. Lejuste F, Thomas L, Picard G, Desestret V, Ducray F, Rogemond $V$ et al. Neuroleptic intolerance in patients with antiNMDAR encephalitis. Neurol Neuroimmunol Neuroinflamm. 2016;3(5):e280. https://doi.org/10.1212/NXI.0000000000000280

4. Titulaer MJ, McCracken L, Gabilondo I, Armangue T, Glaser C, lisuka T et al. Treatment and prognostic factors for long-term outcome in patients with anti-NMDA receptor encephalitis: an observational cohort study. Lancet Neurol. 2013;12(2):157-65. https://doi.org/10.1016/S1474-4422(12)70310-1

5. Wang W, Li JM, Hu FY, Wang R, Hong Z, He L et al. Anti-NMDA receptor encephalitis: clinical characteristics, predictors of outcome and the knowledge gap in southwest China. Eur J Neurol. 2016;23(3):621-9. https://doi.org/10.1111/ene.12911

6. Byrne S, Walsh C, Hacohen Y, Muscal E, Jankovic J, Stocco A et al. Earlier treatment of NMDAR antibody encephalitis in children results in a better outcome. Neurol Neuroimmunol Neuroinflamm. 2015;2(4):e130. https://doi.org/10.1212/NXI.0000000000000130

7. Sartori S, Nosadini M, Cesaroni E, Falsaperla R, Capovilla G, Beccaria F et al. Paediatric anti-N-methyl-D-aspartate receptor encephalitis: the first Italian multicenter case series. Eur J Paediatr Neurol. 2015;19(4):453-63. https://doi.org/10.1016/j.ejpn.2015.02.006

8. Graus F, Titulaer MJ, Balu R, Benseler S, Bien CG, Cellucci T et al. A clinical approach to diagnosis of autoimmune encephalitis. Lancet Neurol. 2016;15(4):391-404. https://doi.org/10.1016/S1474-4422(15)00401-9

9. Dalmau J, Gleichman AJ, Hughes EG, Rossi JE, Peng X, Lai M et al. Anti-NMDA-receptor encephalitis: case series and analysis of the effects of antibodies. Lancet Neurol. 2008;7(12):1091-8. https://doi.org/10.1016/S1474-4422(08)70224-2

10. Florance NR, Davis RL, Lam C, Szperka C, Zhou L, Ahmad S et al. Anti-N-methyl-D-aspartate receptor (NMDAR) encephalitis in children and adolescents. Ann Neurol. 2009;66(1):11-8. https://doi.org/10.1002/ana.21756

11. Irani SR, Bera K, Waters P, Zuliani L, Maxwell S, Zandi MS et al. $\mathrm{N}$-methyl-D-aspartate antibody encephalitis: temporal progression of clinical and paraclinical observations in a predominantly non-paraneoplastic disorder of both sexes. Brain. 2010;133(Pt 6):1655-67. https://doi.org/10.1093/brain/awq113

12. Viaccoz A, Desestret V, Ducray F, Picard G, Cavillon G, Rogemond $\checkmark$ et al. Clinical specificities of adult male patients with NMDA receptor antibodies encephalitis. Neurology. 2014;82(7):556-63. https://doi.org/10.1212/WNL.0000000000000126

13. Zekeridou A, Karantoni E, Viaccoz A, Ducray F, Gitiaux C, Villega F et al. Treatment and outcome of children and adolescents with N-methyl-D-aspartate receptor encephalitis. J Neurol. 2015;262(8):1859-66. https://doi.org/10.1007/s00415-015-7781-9

14. Wright S, Hacohen Y, Jacobson L, Agrawal S, Gupta R, Philip $S$ et al. $\mathrm{N}$-methyl-D-aspartate receptor antibody-mediated neurological disease: results of a UK-based surveillance study in children Arch Dis Child. 2015;100(6):521-6. https://doi.org/10.1136/archdischild-2014-306795

15. Nagappa M, Bindu PS, Mahadevan A, Sinha S, Mathuranath PS, Taly AB. Clinical features, therapeutic response, and follow-up in pediatric anti-n-methyl-D-aspartate receptor encephalitis: experience from a tertiary care university hospital in India. Neuropediatrics. 2016;47(1):24-32. https://doi.org/10.1055/s-0035-1569464

16. Zhang L, Wu MQ, Hao ZL, Chiang SM, Shuang K, Lin MT et al. Clinical characteristics, treatments, and outcomes of patients with anti-N-methyl-d-aspartate receptor encephalitis: A systematic review of reported cases. Epilepsy Behav. 2017;68:57-65. https://doi.org/10.1016/j.yebeh.2016.12.019 